\title{
EFFECT OF GHLORDIAZEPOXIDE UPON EXPERIMENTAL EXTINCTION IN THE STRAIGHT RUNWAY AS A FUNCTION OF PARTIAL REINFORGEMENT IN THE RAT ${ }^{1}$
}

\author{
SHINKURO IWAHARA, NEIICHI NAGAMURA \\ AND TSUNEO IWASAKI ${ }^{2}$ \\ Tokyo University of Education
}

\begin{abstract}
4 groups of rats were trained to run for food in the straight runway. The groups were differentiated in terms of reinforcement schedule $(50 \%$ vs. $100 \%$ reward) and drug condition (saline vs. $20 \mathrm{mg} / \mathrm{kg}$ of CDP). After 64 acquisition trials, the rats in Section I were given 32 extinction trials, half of each group being injected with CDP and half with saline. The rats in Section II were run similarly but with additional 32 extinction trials during which the drug state was changed twice.

A clear-cut drug-learning dissociation effect was found during extinction as well as from acquisition to extinction. CDP retarded extinction ratio after $100 \%$ reward when the drug condition was unchanged from acquisition to extinction. However, the partial-reinforcement effect (PRE) in extinction was not affected by $\mathrm{CDP}$ although the PRE in acquisition was inhibited by the same drug.
\end{abstract}

Iwahara et al. (1966) reported that chlordiazepoxide (CDP) in doses of 10 and $20 \mathrm{mg} / \mathrm{kg}$, i.p., depressed or nullified the partial reinforcement effect (PRE) during acquisition in the straight runway in that the final running speed of the salinetreated rats was superior under $50 \%$ reward to that under $100 \%$ reward, while the difference in speed was reduced under $10 \mathrm{mg} / \mathrm{kg}$ of CDP and the direction of the difference was even reversed under 20 $\mathrm{mg} / \mathrm{kg}$ of the same drug. In addition, the initial running speed was increased by $10 \mathrm{mg} / \mathrm{kg}$ of CDP in comparison with that under saline but the speed in later trials was retarded by CDP in proportion to its dose level.

In the present study, the extinguished behavior in the same runway situation was investigated as functions of schedules

1. This study was supported in part by a Research Grant (1966-7, No. 10033) from the Ministry of Education to Shinkuro Iwahara.

${ }_{2}$ The authors wish to express their appreciation to $\mathrm{Mr}$. T. Nishimoto, and Mr. T. Takayama who conducted most of the experimental work. of reinforcement (50\% vs. $100 \%$ reward) during acquisition, and drug conditions (saline vs. $20 \mathrm{mg} / \mathrm{kg}$ of CDP).

\section{METHOD}

Apparatus. The details of the apparatus used were described elsewhere (Iwahara et al., 1966). In short, it consisted of a start-box $(32 \mathrm{~cm}$ long), a runway $(115 \mathrm{~cm})$, and a goal-box $(40 \mathrm{~cm})$ with side and end walls. All sections were $9 \mathrm{~cm}$ wide and painted gray.

Procedure. The experimental procedure during acquisition was identical to our previous study. The $S \mathrm{~s}$ were maintained at 80 to $90 \%$ of normal body weight during the course of the experiment. Water was continuously available. After 8 day handling and familialization procedure, the animals in Section I were divided into 6 groups based on drug and reward conditions: saline-100\% reward group, saline$50 \%$ reward group, CDP (10 mg $/ \mathrm{kg})-100 \%$ reward group, CDP $(10 \mathrm{mg} / \mathrm{kg})-50 \%$ reward group, CDP $(20 \mathrm{mg} / \mathrm{kg})-100 \%$ reward group and CDP $(20 \mathrm{mg} / \mathrm{kg})-50 \%$ reward group, respectively. Both physiological saline and 
$\mathrm{CDP}^{3}$ were injected intraperitoneally (i. p.) in a $2.5 \mathrm{ml} / \mathrm{kg}$ solution before the initial trial on each of the acquisition and extinction days.

The $S$ was first placed in the start-box; $5 \mathrm{sec}$ later, the door in front of the box was opened and the animal was allowed to traverse the runway. The door was closed to prevent retracing when the rat left the start-box and when it entered the goal-box, the goal-box door was also closed to prevent retracing. The $S$ was removed from the goal-box immediately after eating reward pellets or in case of nonreward after $20 \mathrm{sec}$ and returned to a waiting cage for an intertrial interval of 4 to $5 \mathrm{~min}$.

Both starting-time (ST) and running time (RT) were recorded. ST was the time from the raising of the start-box door to the $S$ 's interruption of a photobeam located $13 \mathrm{~cm}$ in front of the start-box, and RT was measured from the latter to the breaking of a second beam $42 \mathrm{~cm}$ from the end wall of the goal-box. When the $S$ failed to intercept the first beam within $120 \mathrm{sec}$, both ST and RT were scored $120 \mathrm{sec}$ and when the animal did not reach the second beam within $120 \mathrm{sec}$ after the interruption of the first beam, RT was recorded as $120 \mathrm{sec}$. In both cases the trial was concluded. In the present study, only the RT data were analyzed since practically identical results (with larger variations) were obtained in terms of ST as was the case in our previous study (Iwahara et al., 1966).

The $100 \%$ reward $S$ received small food pellets weighing $300 \mathrm{mg}$ in total on each of the 64 acquisition trials which consisted of 2 runs on each of the first 2 days, and 4 runs on the subsequent days. For the $50 \%$ reward $S$, the sequence of rewards over the 64 trials was obtained by repeating the following sequence: $+-+--++--+++-\cdots$ + , which was identical to Wagner's (1963) procedure.

Extinction or $0 \%$ reward trials started on the day following the last acquisition day (i. e., Acquisition Day 17). The rat was given 4 trials per day for 8 days. During extinction

3 The authors are indebted to Takeda Chemical Industries of Tokyo for supplying CDP (Control ${ }^{\circledR}$ ). each group was further divided into 3 subgroups, receiving saline, $10 \mathrm{mg} / \mathrm{kg}$, and $20 \mathrm{mg} /$ $\mathrm{kg}$, i. p. of CDP, respectively. Saline and drugs were injected $30 \mathrm{~min}$ before the initial trial on each of the extinction days.

As the effects of $10 \mathrm{mg} / \mathrm{kg}$ of CDP upon the extinguished behavior as well as upon the acquisition behavior were found to be about intermediate between those of saline and $20 \mathrm{mg} / \mathrm{kg}$ of CDP, the animals treated in Section II were not given $10 \mathrm{mg} / \mathrm{kg}$ of CDP either during acquisition nor during extinction. Although the rats in Section I were given 32 extinction trials, the Section II rats were given 64 extinction trials : 4 trials per day for 16 days (Extinction Days 1 through 16). In Extinction Days 11 to 13 the rats which had been treated with $\mathrm{CDP}$, were run with saline and the saline-treated rats were run with CDP, and on Extinction Days 14 to 16 , the drug condition was further reversed (see Table 1). These additional treatments in Section II were done in order to investigate the dissociation effect, if any, between CDP and learning. Otherwise the Section II rats were run exactly in the same way as had been the Section I rats.

Subjects. The animals in Section I consisted of 6 hooded and 24 albino rats, while the animals in Section II were 23 albino rats. The total 53 animals were all males and of about 2 months of age at the beginning of experimental training.

\section{Results AND Discussion}

The effects of CDP upon partiallyreinforced running speeds of the Section I rats were already reported in our previous study (Iwahara et al., 1966). The results were generally confirmed by the Section II rats. Fig. I indicates the mean running speeds on the first 8 extinction days as well as on the last acquisition day. An analysis of variance was applied to the data (reciprocals of RTs) based on the unweighted Section means. However, neither the main effect due to the Sections (Section I vs. II), nor any interactions associated with the effect were statistically significant. 
As is clear in Fig. 1, the $50 \%$ reward animals ran faster during extinction than did the 100\% reward animals whether they had been treated with saline or CDP during acquisition. The main effect associated with this reward variable was highly significant $(F=30.69, \quad d f=1 / 37$; $p<0.001)$. This finding was in accordance with most of the previous results with normal undrugged rats, and it has been called the partial-reinforcement effect (PRE) as revealed in extinction (c.g., Lewis, 1960), which, however, must be distinguished from the PRE as revealed in acquisition. The latter PRE was found to be inhibited by amobarbital (Wagner, 1963), ethyl alcohol (Nelson \& Wollen, 1965) and CDP (Iwahara et al., 1966).
In fact, this PRE in acquisition is shown in Fig. 1 in that the saline-50\% reward animals ran faster on the last acquisition day than did the saline- $100 \%$ reward animals and the effect was reversed by 20 $\mathrm{mg} / \mathrm{kg}$ of CDP. The result was explained in terms of the drug's depressant effect upon frustration, produced by non-reinforcement (Iwahara et al., 1966).

However, the superior running speed of the CDP-100\% reward animals over the CDP-50\% reward animals disappeared quickly on the first extinction day even when the same drug was administered (Fig. 1), and the interaction between days (final acquisition day vs. first extinction day) and reward (50\% vs. $100 \%$ reward) was statistically significant $(F=5.56, d f=$
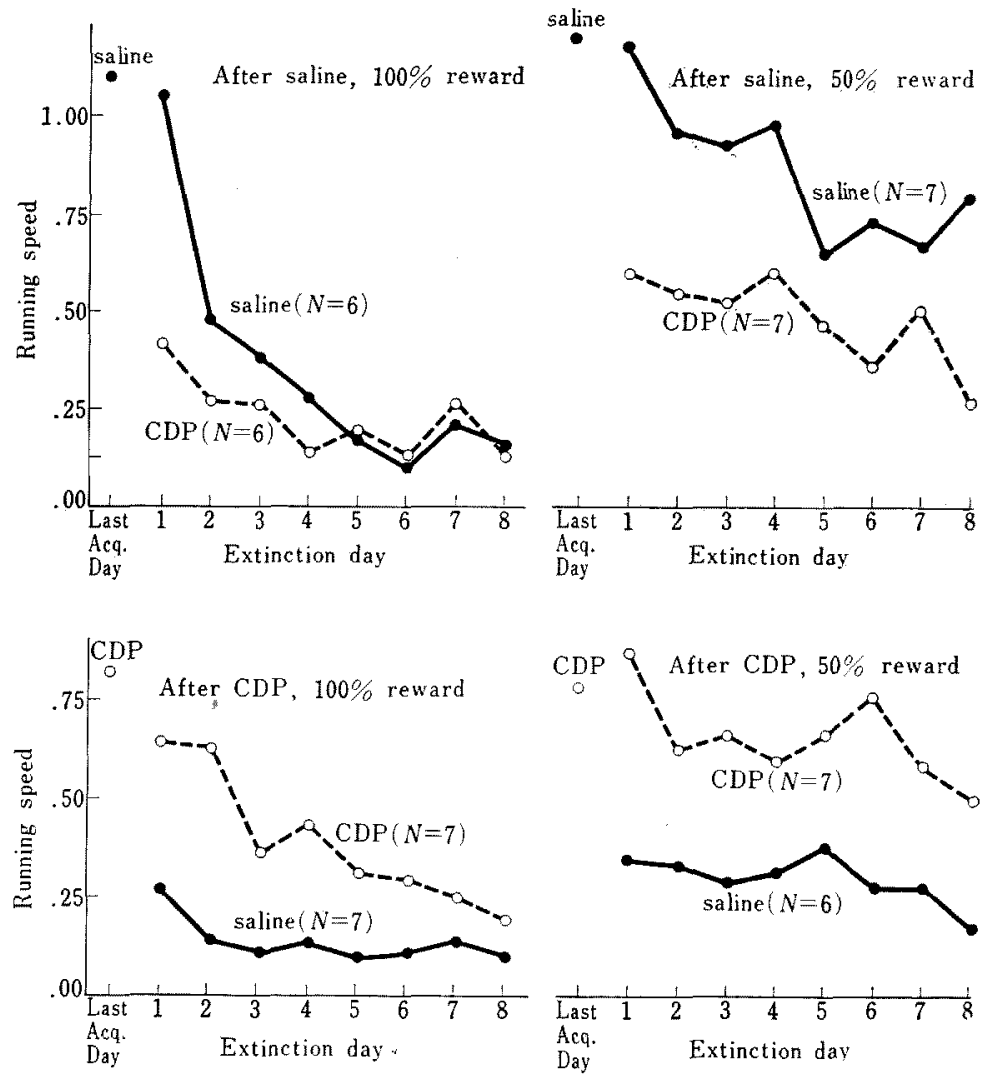

FIo. 1. Running speeds in the straight runway on the last acquisition day and the first 8 extinction days. Minimum possible speed was 0.0067. Data were based on 53 rats in Sections I and II. 
$1 / 12 ; p<0.05)$. That is, although CDP inhibited the PRE as revealed in acquisition, the same drug failed to affect the $P R E$ as revealed in extinction. Thus these two types of the PRE may be quite different in their underlying mechanisms. The present data suggested that the PRE in acquisition is probably due to an emotional factor such as a mediating frustration response (Amsel, 1958), while the PRE in extinction is generally ascribed to a cognitive factor such as generalization decrement or secondary reinforcement (Lewis, 1960). If this assumption is true, CDP is effective upon emotional behavior rather than upon cognitive behavior.

Secondly, the interaction between drug (saline vs. CDP) in training and that in extinction was found to be significant $(F=26.75, d f=1 / 37 ; p<0.001)$. Fig. 1 shows slower running speed after drugstate change, either from saline to CDP or from CDP to saline. Evidently, the internal state induced by CDP functioned like a stimulus but it was not clear from the data whether the drug stimulus may acquire associative connections to running response since the present result could be explained only in terms of stimulus change or generalization decrement. However, it will be shown later in the analyses of the Section II data that the CDPinduced internal stimulus did acquire habit loadings.

This dissociative effect was also called "state-dependent" learning by drugs (Overton, 1964, 1966). The running speed in acquisition in the present data (Fig. 1) as well as in our previous report (Iwahara et al., 1966) was considerably retarded by CDP, but the dissociative effect was much stronger than the drug's ataxic effect because the rats treated with CDP during training, ran considerably slower with saline during extinction than did the rats with CDP during extinction.

Thirdly, when the dissociative effect was controlled; namely when the drug state was not changed from acquisition to extinction, CDP reduced extinction ratio after continuous reinforcement $(100 \%$ reward), since Fig. I indicates a steeper extinction curve in the saline- $100 \%$ reward rats when tested with saline than in the CDP-100\% reward rats when tested with CDP, although the initial running speed was not identical because of the drug's ataxic effect. This discrepancy was most conspicuous on the first 2 extinction days; the reduction in running speed was very slight in the latter animals while the reduction was the largest (among the 8 subgroups) in the former. The interaction between days ( 8 extinction days) and drug (saline vs. CDP) was statistically significant $(F=2.94, d f=7 / 259 ; p<0.01)$. As the minimum possible running speed was 0.007 (reciprocal of $120 \mathrm{sec}$ ) and the final running speeds were much greater than this value, the obtained significant interaction could not be ascribed solely to the "ceiling" effect (in terms of running time).

A similar but less marked trend was observed for the two $50 \%$ reward subgroups whose drug conditions were not changed from acquisition to extinction; the saline-to-saline subgroup reached the slowest speed on Extinction Day 5, while it was Extinction Day 8 for the CDP-toCDP subgroup. However, the data failed to give a significant interaction between days and drug $(F=1.50, d f=7 / 259 ; p>$ $0.05)$. These findings suggested a depressant action of CDP upon frustration, induced by experimental extinction, especially after continuous reinforcement (100\% reward) if the frustration hypothesis of extinction is valid (Lewis, 1960; Kimble, 1961). The present results were in general agreement with the Barry et al. (1962) study in which the rats under alcohol $(1200 \mathrm{mg} / \mathrm{kg}$, i.p.) or amobarbital (20 $\mathrm{mg} / \mathrm{kg}$, i.p.) ran faster than did the saline controls during extinction trials. However according to their study, the drug effects were shown whether the rats had been given acquisition trials (with 100\% 
TABLE 1

Two sets of animals under different drug conditions. The data shown by a solid line in Fig. 2 were based on the animals whose drug conditions were identical in acquisition, Extinction I and III, but different in Extinction II, while the broken-line data were based on the animals whose drug conditions were the same in acquisition and Extinction II, but shifted to the other conditions in Extinction I and III.

\begin{tabular}{cccccc}
\hline $\begin{array}{c}\text { Means in Fig. } 2 \\
\text { shown by }\end{array}$ & Acquis. & Ext. I & $\begin{array}{c}\text { Drug Conditions } \\
\text { Ext. II }\end{array}$ & Ext. III & $\mathcal{N}$ \\
\hline \multirow{2}{*}{ Solid Line } & Saline & Saline & CDP & Saline & 6 \\
& CDP & CDP & Saline & CDP & 6 \\
\hline \multirow{2}{*}{ Broken Line } & Saline & CDP & Saline & CDP & 6 \\
& CDP & Saline & CDP & Saline & 5
\end{tabular}

Notes: Extinction I, II and III refer to Extinction Periods covering Extinction Days 8 to 10,11 to 13 , and 14 to 16 , respectively. Within each of the two sets of the data, the drug conditions as well as reward conditions in acquisition produced practically no differences, and thus these data were pooled and shown in Fig. 2.

food reward) under the same drug or under saline; thus the drug-learning dissociation was not found as was in the present study. The superior running speed of the drugged animals during extinction trials was explained by Barry et al. (1962) in that " these drugs may increase performance by selectively reducing inhibition caused by nonreinforcement" (Barry et al., 1962, p. 467).

As was described earlier, the animals $(\mathcal{N}=23)$ were given additional extinction

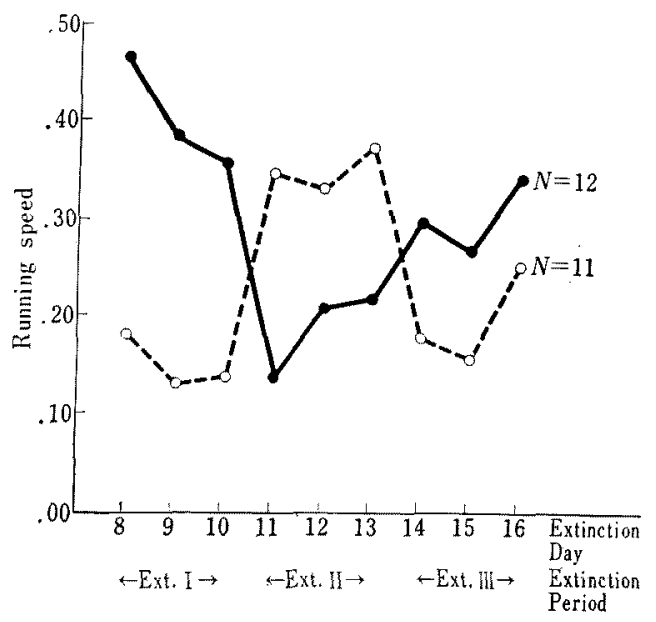

FIG. 2. Running speeds in extinction as a function of change of drug conditions. See Table 1 for the explanation of the solid and broken lines. Data were based on 23 rats in Section II. trials during which the drug conditions were shifted (Table 1). Fig. 2 indicates the mean running speeds of the two sets of animals which were depicted by the solid and broken lines. The solid-line data were based on the animals whose drug conditions (saline or CDP) during acquisition trials, continued until Extinction Day 10 (Extinction I) and then the conditions were changed to the other conditions (either from saline to CDP of from CDP to saline) in Extinction II (Extinction Days 11 to 14 ) and finally shifted back to the original conditions in Extinction III.

On the other hand, the broken-line data were based on the $S_{\mathrm{s}}$ whose drug conditions on Extinction Days 1 to 10 were changed from those in acquisition, and were then shifted back to the original drug conditions, in Extinction II, and finally changed to the other conditions identical to those in Extinction I. Each set of the animals composed of 4 subgroups according to whether the drug condition in acquisition was saline or CDP and whether the reward condition was $50 \%$ or $100 \%$. However as the subgroup data within each set were almost identical, they were pooled and shown in Fig. 2.

As shown in Fig. 2, the animals indicated by the solid line ran faster than those indicated by the broken line in Extinction 
I. That is, the shift in drug state in Extinction I retarded performance and this drug-behavior dissociation effect was already described in this paper based on the first 8-day extinction trials. However, in Extinction II the difference in speed was reversed; the broken-line animals ran faster in Extinction II than in Extinction I and the opposite result was shown in the solid-line animals. This is a clear indication of the associative nature of the internal drug state. The response associated with CDP or saline was so-to-speak " reserved" during the first 10-day extinction trials during which the same response was extinguished under the other condition (saline or CDP). The same dissociative effect appeared in Extinction III.

An analysis of variance of the data yielded a highly significant interaction between the two sets of animals (solid vs. broken lines) and three extinction periods $(F=13.15, d f=2 / 42 ; \quad p<0.001)$. A separate analysis of variance showed significant differences among the three extinction periods for both the solid-line rats $(F=$ $4.77, d f=2 / 11 ; p<0.05)$ and the brokenline rats $(F=10.90, d f=2 / 10 ; p<0.01)$.

The drug-learning dissociation or the reappearance of a learned response to a reinstatement of the drug conditions in acquisition has been studied with various psychotropic drugs, using different experimental apparatus. Overton (1964), for example, trained the rat to escape from shock in a T-maze. The position response learned under pentobarbital (25 $\mathrm{mg} / \mathrm{kg}$, i.p.) failed to appear under saline when the animal was subsequently tested alternately under the drug and saline, and the same dissociative effect was observed when the position discrimination habit was first acquired under saline. In his later report (Overton, 1966), not only pentobarbital $(10,20 \mathrm{mg} / \mathrm{kg}$, i.p.) but also phenobarbital $(60,80 \mathrm{mg} / \mathrm{kg}$, i.p.), ethyl alcohol (2400 mg/kg, i.p.), carbamate (750 mg/kg, i.p.), meprobamate (200 mg/ $\mathrm{kg}$, i.p.), chlorpromazine $(5 \mathrm{mg} / \mathrm{kg}$, i.p.), atropine (150 mg/kg, i.p.), scopolamine (300 mg/kg, i.p.), physostigmine (1 mg/kg, i.p.) and CDP (30 $\mathrm{mg} / \mathrm{kg}$, i.p.) showed a state-dependent learning in the same $T$ maze.

The dissociative effect of GDP was also found by Sachs et al. (1966) who reported that the conditioned avoidance response of the rat trained under $15 \mathrm{mg} / \mathrm{kg}$, i.p. of CDP was reproduced under CDP but not under saline when the drug and saline were alternately given in the subsequent tests.

The present study gives a further evidence of the dissociative effect of CDP under a different drive (hunger) and a different experimental procedure (a straight runway). Similarly, ethyl alcohol was shown to dissociate learning in the rat whether it was run by electric shock (sce above) or by hunger drive (Barry et al., 1965) in the same T-maze situation. However, the state-dependent effect failed to appear in the straight-runway performance motivated by hunger drive under either ethyl alcohol $(1200 \mathrm{mg} / \mathrm{kg}$, i.p.) or amobarbital (20 mg/kg, i.p.) according to Barry et al.'s earlier report (1962) which was referred above in the present study and whose experimental procedure was very similar to the present one. It is not clear why the same dose of alcohol dissociated learning in the $T$-maze but not in the straight runway. Further research is needed to clarify this point.

\section{RefERENCES}

Amsel, A. 1958 The role of frustrative nonreward in non-continuous reward situation. Psychol. Bull., 55, 102-119.

Barry, H. III, Koepfer, E., \& Lutch, J. 1965 Learning to discriminate between alcohol and nondrug condition. Psychol. Rep., 16, 1072.

BARRy, H. III, WAGner, A. R., \& Miller, N. E. 1962 Effects of alcohol and amobarbital on performance inhibited by experimental extinction. J. comp. physiol. Psychol., 55, 464-468.

Iwahara, S., Iwasaki, T., Nagamura, N., \& Masuyama, E. 1966 Effect of chlordiazepoxide upon partially-reinforced behavior of 
rats in the straight runway. Jap. psychol. Res., 8, 131-135.

Krmble, G. A. 1961 Hilgard and Marquis' conditioning and learning. New York: AppletonCentury-Crofts.

Lewis, D.J. 1960 Partial reinforcement: a selective review of the literature since 1950. Psychol. Bull., 57, 1-28.

Nelson, P. S., \& Woller, K. A., 1965 Effects of ethanol and partial reinforcement upon runway acquisition. Psychon. Sci., 3, 135-136.

Overton, D. A. 1964 State-dependent or "dissociated" learning produced with pentobar- bital. J. comp. physiol. Psychol., 57, 3-12.

Overton, D. A. 1966 State-dependent learning produced by depressant and atropine-like drugs. Psychopharmacologia, 10, 6-31.

Sachs, E., Weingarten, M., \& Klein, N. W., Jr. 1966 Effects of chlordiazepoxide on the acquisition of avoidance learning and its transfer to the normal state and other drug conditions. Psychopharmacologia, 9, 17-30.

WAGNER, A. R. 1963 Sodium amytal and partially reinforced runway performance. $J$. exp. Psychol., 65, 474-477.

(Received Sept. 11, 1967) 